\title{
A PERSISTENT PROBLEM WITH SCABIES IN AND OUTSIDE A NURSING HOME IN AMSTERDAM: INDICATIONS FOR RESISTANCE TO LINDANE AND IVERMECTIN
}

\author{
J A van den Hoek (avdhoek@ggd.amsterdam.nl) $)^{1,2}$, J A van de Weerd ${ }^{3}$, T D Baayen ${ }^{1}$, P M Molenaar ${ }^{1}$, G J Sonder ${ }^{1,2}$, \\ I M van Ouwerkerk ${ }^{4}$, H JC de Vries ${ }^{1,5}$ \\ 1. Department of Infectious Diseases, National Institute of Health, Lisbon, Portugal \\ 2. Diseases Prevention and Control Division, Directorate-General of Health, Lisbon, Portugal \\ 3. Sector of Laboratory Assistance, National Institute of Health, Lisbon, Portugal
}

An ongoing outbreak of scabies in and outside a nursing home in Amsterdam is described. Despite standard treatment with lindane and ivermectin, many recurrences were observed which suggested resistance to these drugs. After treatment with $5 \%$ permethrine, the patients were finally cured.

\section{Introduction}

Between September 2007 and March 2008, recurrent scabies occurred among patients and staff members of a nursing home in Amsterdam. All patients could be linked to one "index" patient who died in this nursing home. Outbreaks of scabies in nursing homes are generally caused by patients with a very infectious form of scabies, also called scabies crustosa. In the Dutch guidelines for the treatment of scabies $1 \%$ lindane is foreseen as single treatment, in nursing homes combined with ivermectin $(200 \mu \mathrm{g} / \mathrm{kg})$, to be repeated after one week in case of extensive skin infections. It is recommended to treat asymptomatic contacts prophylactically with either lindane or ivermectin.

\section{Outbreak description}

In November 2007, the Public Health Service (PHS) in Amsterdam was notified that a nursing home doctor in Amsterdam had been diagnosed with scabies and that another staff member who worked in the same nursing home had been diagnosed with scabies in September 2007. At the same time, the nursing home had received information from a hospital in town that a patient, who had been discharged and transferred to the nursing home in August, probably had had scabies at the time despite previous treatments. This "index" patient had died in September 2007.

Subsequent surveillance in the nursing home showed that two of the 15 patients who stayed on the same floor as the index patient, and eight of the 83 staff members who worked on this floor had symptoms of itching. In five of the 10 affected people scabies was diagnosed by detection of mites. In addition to the standard cleaning procedures regarding clothes, bed linen and floor, all people with symptoms of itching or skin eruptions, including their family contacts, were treated with lindane and ivermectin. Contacts without symptoms received ivermectin only. During the following months, the nursing home was advised to survey patients and staff members actively for itching, and to consult a dermatologist to confirm the diagnosis in case scabies was suspected. Information regarding the scabies outbreak was sent to patients who had been discharged from the nursing home since August 2007.

In December 2007, three patients on another floor of the nursing home developed itching. They were treated with lindane, unfortunately without prior consultation of a dermatologist. In January 2008, scabies was diagnosed, through detection of mites, in two further patients living on yet another floor. They were treated with lindane and ivermectin, while the remaining tenants of that floor as well as staff working on that floor were treated prophylactically with ivermectin. Standard cleaning/washing measures were taken.

\section{Recurrence of scabies in the nursing home}

In January 2008 scabies was diagnosed, through detection of mites, for the second time in five staff members. Subsequently they were treated twice with permethrin $5 \%$ and ivermectin with one week interval, and afterwards remained free of scabies symptoms for at least three months.

In February and March 2008, the first recurrences of scabies (diagnosed by detection of mites) were reported in two of the patients who had previously been diagnosed with scabies. A room mate of theirs, who had been treated prophylactically with only ivermectin in 2007, was now also diagnosed with scabies by detecting mites. All three patients were subsequently treated twice with permethrin $5 \%$ and ivermectin. No further recurrences of scabies were diagnosed for at least three months. Asymptomatic room mates were given ivermectin only, also twice with one week interval.

Also in March, three staff members developed scabies (mites detected) who had received prophylactic ivermectin only. After treatment with the revised regimen, they remained free of symptoms for at least three months.

\section{Scabies outside the nursing home}

Before admittance to the nursing home, the index patient had lived in an apartment building with a common laundry. Two co- 
tenants had frequently visited her in the nursing home and were diagnosed with scabies by detecting mites and were subsequently treated with lindane and ivermectin in November 2007. The other users of the laundry in this apartment building were at the same time treated prophylactically with lindane. Standard hygiene measures were taken. In January 2008, these two co-tenants developed recurrent scabies (mites detected) and now received ivermectin twice with one week interval. In late February, they had recurrent scabies again (mites detected). Only after treatment with permethrin $5 \%$ and ivermectin they remained symptom-free for at least three months.

The daughter in law of the index patient and her husband had suffered from scabies and received repetitive treatments with lindane and ivermectin since September 2007. They contacted the PHS in March 2008 because the treatment had still not been successful. After treatment with $5 \%$ permethrin, they remained free of scabies symptoms.

In November 2007 the PHS was notified that an ex-tenant of the nursing home was diagnosed with scabies (mites detected). After treatment with lindane she had recurrent scabies in February 2008. After treatment with permethrin $5 \%$ and twice with ivermectin, she remained free of scabies symptoms.

In February 2008, the PHS was notified of yet another recurrent scabies diagnosis (mites detected) in a hospitalised patient who had stayed in the nursing home in September 2007 and developed symptoms of itching after his stay. Having received the information letter from the nursing home, he had been treated for scabies in November 2007 with lindane and ivermectin. When he was hospitalised in December, he was again diagnosed with scabies and treated with lindane and ivermectin for the second time. In February, when he was admitted to hospital again, it appeared that he was still suffering from scabies. He then received the revised treatment, but the results could not be evaluated as he died shortly after.

Also in February 2008, a dermatologist reported an out-patient with scabies crustosa to the PHS. This patient had stayed in the nursing home together with the index patient. She developed symptoms of itching after her stay. Having received the information letter, she had been treated twice with both lindane and ivermectin. As the itching persisted after treatment, she received corticosteroids and subsequently developed scabies crustosa. Three contacts of this patient also to had complaints of itching. This patient, as well as her contacts, later received permethrin $5 \%$ and ivermectin and remained free of scabies symptoms.

\section{Discussion}

Despite treatment, the correct application of hygienic measures and the prophylactic treatment of contacts, a large number of people developed recurrent scabies in the course of the described outbreak. All of them could be linked to the index patient, who had been treated for various episodes of scabies prior to her stay in the nursing home. Only after treatment with permethrin 5\% all involved patients finally got rid of their scabies and remained symptom-free during a follow-up of at least three months. We therefore consider it most likely that resistance to lindane and ivermectin may have played a role in this outbreak [1].
This observational report is the first in the Netherlands which indicates a likely resistance of scabies mites to lindane and ivermectin. Outside the Netherlands, resistance to lindane has been described in vivo and in vitro [2,3], and for that reason, lindane is not prescribed anymore in the United States; permethrin $5 \%$ is now the first choice of treatment [4]. There is only one publication on resistance of scabies mites to ivermectin [3]. But in vitro studies have shown that over a period of 10 years, the survival time of the mite has doubled [5]. Resistance to ivermectin should be considered in situations where scabies in not endemic and patients remain having complaints despite treatment [6].

\section{Conclusion}

This outbreak of scabies was difficult to control. According to the information obtained from the patients involved in this outbreak, re-infection was not likely. It was more likely that the mites causing this outbreak were not susceptible to lindane and ivermectin.

Note: the issue regarding resistance to lindane is not relevant any more since in the summer of 2008 this drug has been taken off the Dutch market for environmental reasons.

\section{Acknowledgements:}

We acknowledge the support of Aura Timen, Jim van Steenbergen, Yvonne van Duynhoven, Edwin van Leent, Marianne Siebbeles, Jacqueline Wesselink and Lian Bovee.

This report is based on a report in Dutch published in the Dutch public health bulletin [7].

References

1. Purvis RS, Tyring SK. An outbreak of lindane-resistant scabies treated successfully with permethrin 5\% cream. J Am Acad Dermatol. 1991;25(6 Pt 1):1015-6.

2. Heukelbach J, Feldmeier H. Scabies. Lancet. 2006;367(9524):1767-74.

3. Currie BJ, Harumal P, McKinnon M, Walton SF. First documentation of in vivo and in vitro ivermectin resistance in Sarcoptes scabiei. Clin Infect Dis. 2004:39(1):e8-12.

4. National Center for Zoonotic, Vector-Borne, and Enteric Diseases, Division of Parasitic Diseases. Parasites and Health: Scabies [homepage on the internet]. Atlanta: Centers for Disease Control and Prevention. Available from: http:// www.dpd.cdc.gov/dpdx/html/scabies.htm [accessed 8 April 2008].

5. Mounsey KE, Holt DC, McCarthy J, Currie BJ, Walton SF. Scabies: molecular perspectives and therapeutic implications in the face of emerging drug resistance. Future Microbiol. 2008;3(1):57-66.

6. Walton SF, Currie BJ. Problems in diagnosing scabies, a global disease in human and animal populations. Clin Microbiol Rev. 2007;20(2):268-79.

7. van den Hoek A, van de Weerd J, Baayen D, Molenaar P, Sonder G, et al. Hardnekkig probleem met scabies in Amsterdam: resistentie teren lindaan en ivermectine? [Persistant problem with scabies in Amsterdam: resistance against lindane and ivermectin?]. [In Dutch]. Infectieziektenbulletin;2008:19:204-6. Available from: http://www.rivm.nl/cib/publicaties/bulletin/jaargang_19/bull1906/ scabies.jsp

This article was published on 27 November 2008.

Citation style for this article: van den Hoek JA, van de Weerd JA, Baayen TD, Molenaar PM, Sonder GJ, van Ouwerkerk IM, de Vries HJ. A persistent problem with scabies in and outside a nursing home in Amsterdam: indications for resistance to lindane and ivermectin. Euro Surveill, 2008:13(48):pij=19052. Available online: http://wwm. eurosurveillance.org/ViewArticle.aspx? 